\title{
Influence of hay and animal feed exposure on respiratory status: a longitudinal study
}

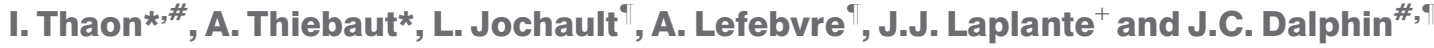

ABSTRACT: Our aim was to study respiratory symptoms and lung function decline in farmers, with particular attention to the influence of handling hay, straw and animal feed.

From a cohort recruited in 1993-1994, 219 (82.6\%) dairy farmers, 130 (62.5\%) nondairy agricultural workers and 99 (66.4\%) controls were re-evaluated in 2006 . They answered medical and occupational questionnaires, underwent spirometric tests at both evaluations and pulse oximetry in 2006.

Dairy and nondairy agricultural workers showed an increased risk for usual morning phlegm (adjusted OR 4.27 (95\% Cl 1.41-12.95) and 3.59 (95\% Cl 1.16-11.10), respectively). Animal feed handling was associated with increased risks of wheezing $(p=0.01)$ and usual morning phlegm $(p=0.04)$; hay or straw handling was associated with increased risk of wheezing $(p=0.008)$. Adjusting for smoking, age, height, sex and altitude, dairy farmers had greater declines in forced expiratory volume in $1 \mathrm{~s}\left(F E V_{1}\right)$ /forced vital capacity ratio $(p=0.01)$ than controls. An increased decline in FEV 1 for all agricultural workers was associated with animal feed handling, both measured as a categorical (currently versus never handling; $p=0.05$ ) or quantitative value (years of exposure during the survey period; $p=0.03$ ).

Hay, straw or animal feed handling represents a risk factor of bronchial symptoms and, for animal feed only, of accelerated decline in expiratory flows.

KEYWORDS: Asthma, chronic bronchitis, farming, longitudinal studies, respiratory function tests

$\mathbf{A}$ $\mathrm{n}$ increased risk of chronic bronchitis has been demonstrated in various agricultural groups [1], notably in swine confinement workers [2,3], poultry workers [4, 5] and dairy farmers [6-9]. Several cross-sectional studies have reported lung function impairment in agricultural workers [10,11], including dairy farmers [8, 9]. An accelerated decline in lung function has been suggested in swine confinement workers [12, 13] and grain handlers [14]. The results of two controlled longitudinal studies we conducted in French dairy farmers in 1986 and 1994 were discordant. In the 1986 cohort, we found an accelerated decline in forced vital capacity (FVC) and forced expiratory volume in 1 s (FEV1) in dairy farmers at 5-yr follow-up [15], but these results were not confirmed at the second follow-up 12 yrs after inclusion [16]. This may be due to an improvement in working conditions leading to a decrease in agricultural exposure over time, as suggested by studies in grain elevator workers [17]. In the 1994 cohort, dairy farmers showed an accelerated decline in FEV1/FVC at 6-yr follow-up compared with controls [18]. Hence, the present study aimed to compare lung function decline for a 12-yr follow-up period in the 1994 cohort between dairy farmers, nondairy agricultural workers and controls, and to explore the influence of two situations that engender exposure to organic dust (hay or straw and animal feed handling) in dairy and nondairy agricultural workers.

\section{METHODS}

\section{Population}

The study population consisted of three groups of both sexes, aged 16-66 yrs (at baseline), living in the same rural area in the Doubs province of France. Subjects were selected from the Doubs Mutualité Sociale Agricole (MSA; Agricultural Health Insurance Mutual) medical files. Every 5 years, the MSA medical unit organises free medical examinations for all affiliated members. For the 1993-1994 examinations, we opened recruitment to 353 dairy farmers, 278 nondairy agricultural workers (poultry farmers, swine workers, fish farmers, beekeepers, herdsmen, cattle inseminators, cheesemakers and forestry workers) and 189 controls (administrative employees from agricultural companies). From February 1993 to May 1994, 265 dairy farmers, 208 nondairy agricultural workers and 149 controls participated in the first investigations (T1). The $\mathrm{T} 1$ results, which compared dairy farmers
AFFILIATIONS

*Occupational Diseases Dept,

'Chest Diseases Dept, University Hospital of Besançon, \#UMR 6249 CNRS/Université de Franche-Comté, Laboratoire Chronoenvironnement, and

${ }^{+}$Mutualité Sociale Agricole of Besançon, Besançon, France.

CORRESPONDENCE

J.C. Dalphin

Dept of Chest Diseases CHU - Hôpital Jean Minjoz Boulevard Fleming 25030 Besançon Cedex France E-mail: jean-charles.dalphin@univfcomte.fr

Received:

July 312009

Accepted after revision: Aug 082010 First published online: Oct 282010 
and controls, were published in 1998 [9]. In 1999 (T2), identical investigations were conducted on the same farmers and controls [18].

In 2006 (T3), we decided to re-evaluate respiratory symptoms and lung function in this 1994 cohort including nondairy agricultural workers. An explanatory letter concerning the objectives and practical value of the study was sent to all surviving 1993-1994 participants (16 subjects had died). Those who agreed to participate were re-evaluated at the same time of year (winter or spring) as for the two previous analyses. Subjects who agreed to participate but could not come to the medical examination (having moved to another province, for example) were asked to answer the questionnaires and return them by post. The protocol comprised a medical and occupational questionnaire, spirometric tests in 1994 and 2006, and a noninvasive measure of blood oxygen saturation (arterial oxygen saturation measured by pulse oximetry; $\mathrm{Sp}_{\mathrm{p}} \mathrm{O}_{2}$ ) in 2006 only.

This study respects the European Respiratory Society (ERS) principles for research involving humans and was approved by the local ethics committee (Comité consultatif de protection des personnes dans la recherche biomedicale de FrancheComté, Besançon, France).

\section{Questionnaires}

Occupational and medical questionnaires were sent by post 10 days before the scheduled medical examination and were collected during the check-up examination. The medical questionnaire was based on the American Thoracic Society (ATS) questionnaire [19] and on the long version of the European Community Respiratory Health Survey questionnaire [20]. Chronic bronchitis was defined as cough and expectoration for $\geqslant 3$ months of the year for at least two consecutive years. Questions on smoking habits, respiratory symptoms, and history of allergy have been defined previously [9].

The occupational questionnaire was designed by the authors in collaboration with engineers and technicians from the local Department of Agriculture and the MSA. Some questions have been added to the version used in previous studies $[9,16,18]$. Working status in 2006 was designated as: "still working" (at the same or another job), "retired", and "unemployed or having stopped working for personal reasons". Dairy and nondairy agricultural workers were asked if they handled hay or straw, and animal feed (including grain and flour but not hay) "never", "currently" (in 2006) or "formerly" (stopped before 2006).

\section{Respiratory function tests}

Respiratory function tests were performed according to ATS recommendations [21] with a portable pneumotachograph (SpiroPro; Sensormedics, Voisins le Bretonneux, France). A minimum of three adequate measures of FVC, FEV1, forced expiratory flow at $25-75 \%$ of FVC (FEF25-75\%) and forced peak expiratory flow (PEF) were taken, and the best blow was selected. The spirometer was calibrated daily for atmospheric pressure, hygrometry and temperature. Values were expressed as absolute values and as percentages of European Community for Steel and Coal (ECSC) reference values, calculated in relation to sex, age and height [22].

\section{Oximetry data}

For each subject, $\mathrm{Sp}_{\mathrm{p}} \mathrm{O}_{2}$ and pulse rate were evaluated with a finger pulse oximeter Onyx® model 9500 (Nonin Medical Inc., Minneapolis, MN, USA). Three measurements were performed at 30-s intervals after subjects had spent $\geqslant 30 \mathrm{~min}$ in a heated room, seated for $\geqslant 15 \mathrm{~min}$. The highest $S_{p}, \mathrm{O}_{2}$ value and corresponding pulse rate were retained.

\section{Data analysis}

A first series of analyses was carried out on the 2006 crosssectional data. Each respiratory symptom was cross-tabulated by farming (dairy farmers, nondairy farmers and controls), age, sex, smoking status (current smokers, ex-smokers and never-smokers), altitude $(<400,400-800$ and $>800 \mathrm{~m})$ and employment status. Associations between farming groups (reference controls) and respiratory symptoms were evaluated by multiple logistic regressions adjusted for age and smoking. Respiratory symptoms were compared with the same models in dairy and nondairy agricultural workers for subjects having handled hay or straw (first: currently and/or formerly; secondly and separately: currently or formerly) and for those never having handled hay or straw. The same factors were compared for the animal feed handling.

Secondly, the relationship between lung function in 2006, $\mathrm{Sp}, \mathrm{O}_{2}$ and exposure was analysed with multiple linear regression models adjusted for age, smoking, sex, height, altitude and, for $\mathrm{Sp}_{\mathrm{p}} \mathrm{O}_{2}$ only, pulse rate and $\mathrm{FEV} 1 \%$ predicted.

Finally, longitudinal analyses of respiratory function were performed. The effect of farming (dairy and nondairy agricultural workers versus controls) on the annual change in lung function parameters between T1 and T3 (2006 value 1994 value/number of years between the T1 and T3 examinations) was tested by multiple linear regressions adjusted for age, smoking, sex, height, altitude and initial value of the parameter in 1994. Then, multiple linear regression models were used to analyse the relationship between annual change in respiratory parameters and hay or straw handling, or animal feed handling coded as a categorical (currently or formerly versus never) and quantitative (years of exposure between T1 and T3) value. The level of significance was set at $p<0.05$, but all p-values $<0.10$ are reported. Statistical analyses were carried out using the SAS 9.1.3 package (SAS Institute Inc., Cary, NC, USA).

\section{RESULTS}

Of the 622 subjects who had participated in 1994, 174 were not available for the 2006 study: 11 dairy farmers, two nondairy agricultural workers and three controls died before 2006, 20 dairy farmers, 20 nondairy agricultural workers and seven controls refused to participate, and 15 dairy farmers, 56 nondairy agricultural workers and 40 controls were lost to follow-up. Therefore, 219 (82.6\%) dairy farmers, 130 (62.5\%) nondairy agricultural workers and $99(66.4 \%)$ controls participated in the 2006 follow-up. $33(7.4 \%)$ out of the 448 participants only returned their occupational and medical questionnaires. The subjects lost to follow-up or who refused to participate were: more often male (69.5 versus $60.3 \%$; $\mathrm{p}=0.03$ ) and more often current smokers in 1994 (34.8 versus $19.2 \% ; \mathrm{p}<0.001)$ than those who participated. They were also younger (mean age at baseline 38.5 versus 42.2 yrs; $\mathrm{p}=0.0007$ ). 
There was no difference in respiratory symptoms or lung function parameters at baseline between subjects who did or did not participate in the follow-up.

The main characteristics and comparison of the three exposure groups for the 12-yr follow-up participants are reported in table 1. Dairy farmers were more often never-smokers than controls and nondairy agricultural workers were more often current smokers than controls. However, at baseline, dairy farmers were older (mean age 45.8 yrs) and more often neversmokers $(75.3 \%)$ than nondairy agricultural workers (mean age 38.4 yrs; never-smokers 52.3\%) and controls (mean age 37.9 yrs; never-smokers 57.8\%). In 2006, 166 (37.5\%) subjects had already stopped working and 280 were still working; however, lung function parameters at baseline did not differ between the two groups.

\section{Respiratory symptoms in 2006}

Six dairy farmers with hypersensitivity pneumonitis were excluded from the following analyses. Respiratory diseases (asthma, chronic bronchitis, emphysema and pulmonary infections) were more frequent in dairy farmers (OR 2.85, $95 \%$ CI 1.20-6.80) than in controls. The prevalence of respiratory symptoms in the three exposure groups is presented in table 2. After adjustment for age and smoking, usual morning phlegm was more frequent both in dairy farmers (OR 4.27, 95\% CI 1.41-12.95) and in nondairy agricultural workers (OR 3.59, 95\% CI 1.16-11.10) than in controls. In the same model, usual morning phlegm was also more frequent in current and former smokers than in neversmokers (OR 4.88 (95\% CI 2.10-11.34) and OR 2.29 (95\% CI 1.15-4.57), respectively).

Farmers handling or having handled hay or straw seemed to be at an increased risk of wheezing and personal history of allergy. The age- and smoking-adjusted OR was 3.49 (95\% CI 1.43-8.54) for wheezing at any time in their life and 1.55 (95\% CI 1.16-2.07) for personal history of allergy. They also reported waking up more during the night due to coughing (adjusted OR 2.73, 95\% CI 1.02-7.31).

TABLE 1 Main characteristics of the participants in 2006 in the three exposure groups

\begin{tabular}{|c|c|c|c|c|c|}
\hline & All & Dairy farmers & $\begin{array}{c}\text { Nondairy agricultural } \\
\text { workers }^{\#}\end{array}$ & Controls & p-value \\
\hline Subjects & $448(100.0)$ & $219(48.9)$ & $130(29.0)$ & $99(22.1)$ & \\
\hline Age yrs & $54.8 \pm 11.4$ & $58.0 \pm 11.1$ & $52.0 \pm 11.2$ & $51.2 \pm 10.0$ & $<0.0001$ \\
\hline \multicolumn{6}{|l|}{ Sex } \\
\hline Male & $270(60.3)$ & $123(56.2)$ & $99(76.2)$ & $48(48.5)$ & $<0.0001$ \\
\hline Never & $273(61.0)$ & $159(72.6)$ & $62(47.7)$ & $52(52.5)$ & $<0.0001$ \\
\hline Currently & 49 (10.9) & $15(6.8)$ & $22(16.9)$ & $12(12.1)$ & \\
\hline Formerly & $126(28.1)$ & $45(20.6)$ & $46(35.4)$ & $35(35.4)$ & \\
\hline Exposure pack-yrs & $25.5 \pm 20.8$ & $28.3 \pm 25.8$ & $23.9 \pm 16.0$ & $24.1(20.0)$ & $<0.0001$ \\
\hline \multicolumn{6}{|l|}{ Altitude } \\
\hline Plain $<400 \mathrm{~m}$ & $218(48.7)$ & $118(53.9)$ & $49(37.7)$ & $51(51.6)$ & \\
\hline \multicolumn{6}{|l|}{ Working status in 2006} \\
\hline Working in the same or another job & $280(62.5)$ & $118(53.9)$ & $90(69.2)$ & $72(72.7)$ & $<0.0001$ \\
\hline Retired & $151(33.3)$ & $97^{+}(44.3)$ & 35 (26.9) & $19(20.0)$ & \\
\hline Unemployed or stopped working for other reasons & $17(4.2)$ & $4^{\S}(1.8)$ & $5^{f}(3.9)$ & $8^{f}(8.1)$ & \\
\hline \multicolumn{6}{|l|}{ Hay or straw handling } \\
\hline Never & $93(27.3)$ & $39(18.2)$ & $54(42.5)$ & & \\
\hline Formerly & $128(37.5)$ & $80(37.4)$ & $48(37.8)$ & & \\
\hline Currently & $120(35.2)$ & $95(44.4)$ & $25(19.7)$ & & \\
\hline \multicolumn{6}{|l|}{ Animal feed handling i.e. grains } \\
\hline Never & $109(32.1)$ & $43(20.1)$ & $66(52.4)$ & & \\
\hline Formerly & $141(41.5)$ & $101(47.2)$ & $40(31.7)$ & & \\
\hline Currently & $90(26.5)$ & $70(32.7)$ & $20(15.9)$ & & \\
\hline
\end{tabular}

Data are presented as $\mathrm{n}(\%)$ or mean $\pm \mathrm{SD}$, unless otherwise stated. Chi-squared tests were used for qualitative variables; unpaired t-tests were used for quantitative variables. ${ }^{*}$ : including 40 farmers (23 poultry workers, two pig farmers, two fish farmers, two agricultural labourers, one beekeeper and nine flower cultivators), 11 people with regular contact with cattle (three herdsmen, seven cattle inseminators, two cattle-lorry drivers and a slaughterhouse worker), two subjects in regular contact with grain (one grain silo worker and one miller), 42 forestry or sawmill workers, 24 cheesemakers and nine subjects who frequently went to the dairy farms (six milk quality control technicians or collectors and three agricultural machine mechanics); ${ }^{\bullet}$ : for current and ex-smokers; ${ }^{+}$: two retired farmers had stopped work before retirement age due to respiratory diseases (asthma or farmer's lung disease); ${ }^{\text {s: }}$ only one farmer stopped working due to asthma; $f$ : no subject stopped working due to respiratory diseases. 


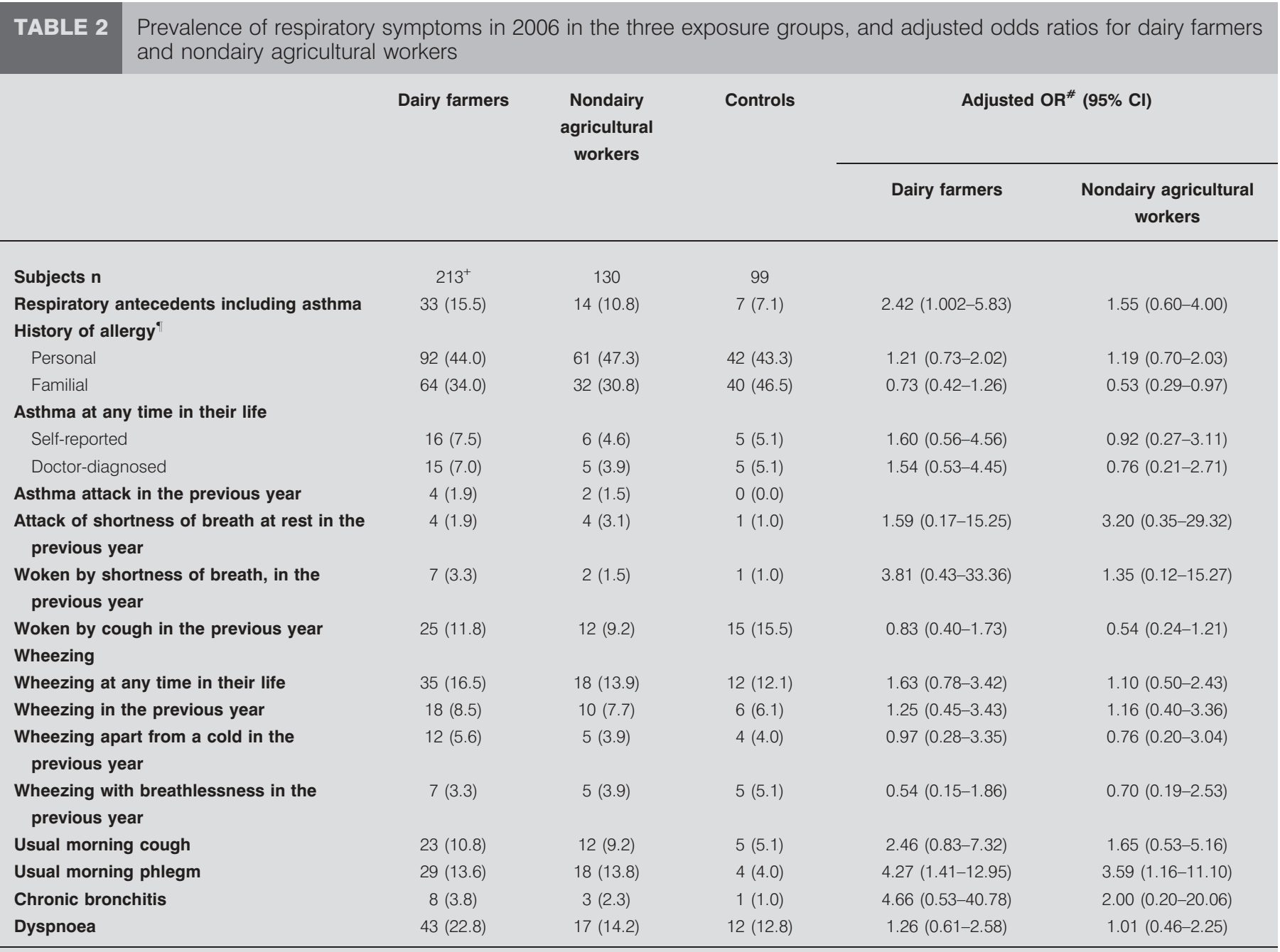

Data are presented as $n(\%)$, unless otherwise stated. Unexposed controls were used as the reference group.. : adjusted for age and smoking (never-smokers were used as the reference group for this adjustment); ${ }^{*}$ : nasal allergies including hay fever, eczema or any kind of skin allergy, or allergy to insect stings or bites; ${ }^{+}$: six farmers with hypersensitivity pneumonitis were excluded.

Farmers handling or having handled animal feed seemed to present increased risks of wheezing at any moment in their life (adjusted OR 2.40, 95\% CI 1.14-5.04). They also reported waking up more during the night due to coughing (adjusted OR 2.95, 95\% CI 1.17-7.39) and more usual morning cough (adjusted OR 2.75, 95\% CI 1.03-7.29).

Subjects who had stopped handling hay or straw, or animal feed had higher risks of respiratory symptoms (table 3).

\section{Lung function in 2006}

In 2006, dairy farmers had lower PEF (mean 101.7 versus $109.0 \%$ pred; $\mathrm{p}=0.007)$, FEV1/FVC (100.1 versus $102.6 \%$ pred; $\mathrm{p}=0.07$ ) and $\mathrm{FEF} 25-75 \%$ (81.3 versus $87.7 \%$ pred; $\mathrm{p}=0.08$ ) than controls. Current smokers had lower FEV1 $(\mathrm{p}=0.05)$ and FEV1/ FVC $(p=0.05)$ than never-smokers. Dairy farmers also had lower $\mathrm{Sp}_{\mathrm{p}} \mathrm{O}_{2}$ than controls (96.06 versus $96.68 \%$; $\mathrm{p}=0.02$ after adjustment for age, smoking, height, sex, altitude, pulse rate and FEV1).

\section{Lung function decline during follow-up}

Lung function parameter decline during follow-up in the three exposure groups is presented in table 4 . Dairy farmers had greater declines in FEV1 and FEV1/FVC than controls $(p=0.04$ and $\mathrm{p}=0.007$, respectively). After adjustment for smoking, age, height, sex and altitude (table 5), dairy farmers still had a greater decline in FEV1/FVC $(p=0.01)$ than controls. Nondairy agricultural workers also showed an increased decline in FEV1/FVC and in FEF25-75\% but these differences did not reach the level of significance. Current handling of animal feed was associated with an increased decline in FEV1 $(p=0.05$; table 5). Moreover, decline in FEV1 increased with years spent handling animal feed during the survey period $\mathrm{T} 1$ to $\mathrm{T} 3(\mathrm{p}=0.03$; table 5). Current smoking was also associated with an accelerated decline in FEV1 $(p=0.02)$, FEV1/FVC $(p=0.02)$ and FEF $25-75 \%(p=0.0003)$.

\section{DISCUSSION}

An increased risk of respiratory symptoms related to chronic bronchitis (usual morning phlegm and, to a lesser degree, 
TABLE 3 Influence of farming exposure on respiratory symptoms in farmers ${ }^{\#}$

\begin{tabular}{|c|c|c|c|c|}
\hline & \multicolumn{2}{|c|}{ Hay or straw handling } & \multicolumn{2}{|c|}{ Animal food handling } \\
\hline & Current $^{\top}$ versus never ${ }^{+}$ & Former $^{5}$ versus never ${ }^{+}$ & Current $^{f}$ versus never $\# \#$ & Former" versus never ${ }^{\# \#}$ \\
\hline Personal history of allergy & $1.51(0.84-2.71)$ & $2.31(1.29-4.14)$ & $1.26(0.70-2.25)$ & $1.79(1.03-3.09)$ \\
\hline \multicolumn{5}{|l|}{ Asthma at any time in their life } \\
\hline Self-reported & $1.20(0.21-6.82)$ & $8.37(1.78-39.25)$ & $0.50(0.09-2.84)$ & $5.69(1.53-17.04)$ \\
\hline Wheezing at any time in their life & $2.21(0.81-6.01)$ & $4.99(1.93-12.88)$ & $1.25(0.48-3.20)$ & $3.58(1.60-8.00)$ \\
\hline Wheezing in the previous year & $1.26(0.31-5.01)$ & $3.31(1.06-10.36)$ & $1.61(0.38-6.85)$ & $3.55(1.13-11.15)$ \\
\hline Wheezing apart from a cold in the previous year & $1.10(0.14-8.40)$ & $4.67(0.99-21.95)$ & $2.99(0.45-19.80)$ & $3.65(0.77-17.35)$ \\
\hline Usual morning cough & $1.34(0.44-4.09)$ & $2.11(0.78-5.68)$ & $2.21(0.64-7.49)$ & $3.04(1.09-8.50)$ \\
\hline Usual morning phlegm & $1.91(0.76-4.88)$ & $2.26(0.94-5.45)$ & $1.14(0.48-2.74)$ & $1.21(0.57-2.59)$ \\
\hline Chronic bronchitis ${ }^{++}$ & & & $2.63(0.23-30.44)$ & $7.39(0.85-64.16)$ \\
\hline
\end{tabular}

usual morning cough) was found in dairy farmers and nondairy agricultural workers. Dairy farmers also presented an increased decline in $\mathrm{FEV} 1 / \mathrm{FVC}$ and lower $\mathrm{Sp}_{\mathrm{p}} \mathrm{O}_{2}$ than controls. Animal feed and hay or straw handling were associated with increased risks of respiratory symptoms and animal feed handling was associated with an increased decline in FEV1. Finally, we found a healthy worker effect indicated by the stronger effect of animal feed, hay and straw handling observed in former than in the current handlers.

This longitudinal study has limitations. We have no measurements of exposure associated with hay, straw or animal feed handling. These parameters were evaluated by self-report questionnaires previously used in dairy farmer studies conducted in the same province [16, 18, 23], one of which included measurements of hay and fodder contamination by microorganisms [23]. We observed high levels of hay contamination by microorganisms, especially in relation to low modernity of farms [23-25] and to bad climatic conditions during haymaking season. In particular, we highlighted a large variability in results, in that the concentration of microorganisms differed considerably between farms as well as within the same farm, depending on the time of day and where measurements were taken with respect to work patterns and the time of year [26]. The conditions inherent to this type of longitudinal study, with a 12-yr follow-up, made it extremely difficult to reach an accurate estimate of the level of professional exposure. In our study, animal feed, hay and straw handling were strongly related: only $24.4 \%$ had discordant exposures to animal feed and hay or straw. Similarly, in a cross-sectional study recently published on farmers lung function and including personal measurements of exposures to dust, microorganisms and gas, many agents were strongly correlated [27]. In our study, these correlations of exposures limit the possibility of forming

TABLE 4 Annual changes in respiratory function parameters between 1994 and 2006

\begin{tabular}{lccc} 
& Dairy farmers & $\begin{array}{c}\text { Nondairy agricultural } \\
\text { workers }\end{array}$ \\
\hline Time between the two surveys yrs & $12.7 \pm 0.29$ & $12.4 \pm 0.40$ & $12.5 \pm 0.41$ \\
Respiratory function & & $157^{\#}$ & 72 \\
Available data $\mathrm{n}$ & $-10.7 \pm 29.6$ & $-12.6 \pm 37.1$ & $-11.0 \pm 42.7$ \\
$\Delta \mathrm{FVC} \mathrm{mL} \cdot \mathrm{yr}^{-1}$ & $-16.4 \pm 30.0^{*}$ & $-14.0 \pm 27.9$ & $-8.2 \pm 23.0$ \\
$\Delta \mathrm{FEV} 1 \mathrm{~mL} \cdot \mathrm{yr}^{-1}$ & $-0.21 \pm 0.64^{+}$ & $-0.11 \pm 0.41$ & $0.005 \pm 0.57$ \\
$\Delta \mathrm{FEV} 1 / \mathrm{FVC} \% \cdot \mathrm{yr}^{-1}$ & $33.2 \pm 112.1^{\S}$ & $65.4 \pm 125.4$ & $64.0 \pm 118.9$ \\
$\Delta \mathrm{PEF} \mathrm{mL} \cdot \mathrm{s}^{-1} \cdot \mathrm{yr}^{-1}$ & $-41.5 \pm 57.4^{f}$ & $-41.4 \pm 60.0^{* *}$ & $-20.7 \pm 58.2$ \\
$\Delta \mathrm{FEF} 25-75 \% \mathrm{~mL} \cdot \mathrm{s}^{-1} \cdot \mathrm{yr}^{-1}$ & & & \\
\hline
\end{tabular}

Data are presented as mean \pm SD, unless otherwise stated. Change: (2006 value -1994 value)/(number of years between the T1 and T3 examinations). $\Delta$ : change in; FVC: forced vital capacity; FEV1: forced expiratory volume in $1 \mathrm{~s}$; PEF: peak expiratory flow; FEF25-75\%: forced expiratory flow at $25-75 \%$ of FVC. ${ }^{\#}$ : six farmers with hypersensitivity pneumonitis were excluded (only four had valid respiratory function tests); ${ }^{\prime}: p=0.04 ;{ }^{+}: p=0.007 ;{ }^{\varsigma}: p=0.07 ;{ }^{f}: p=0.02 ;{ }^{* \star}: p=0.01$. 


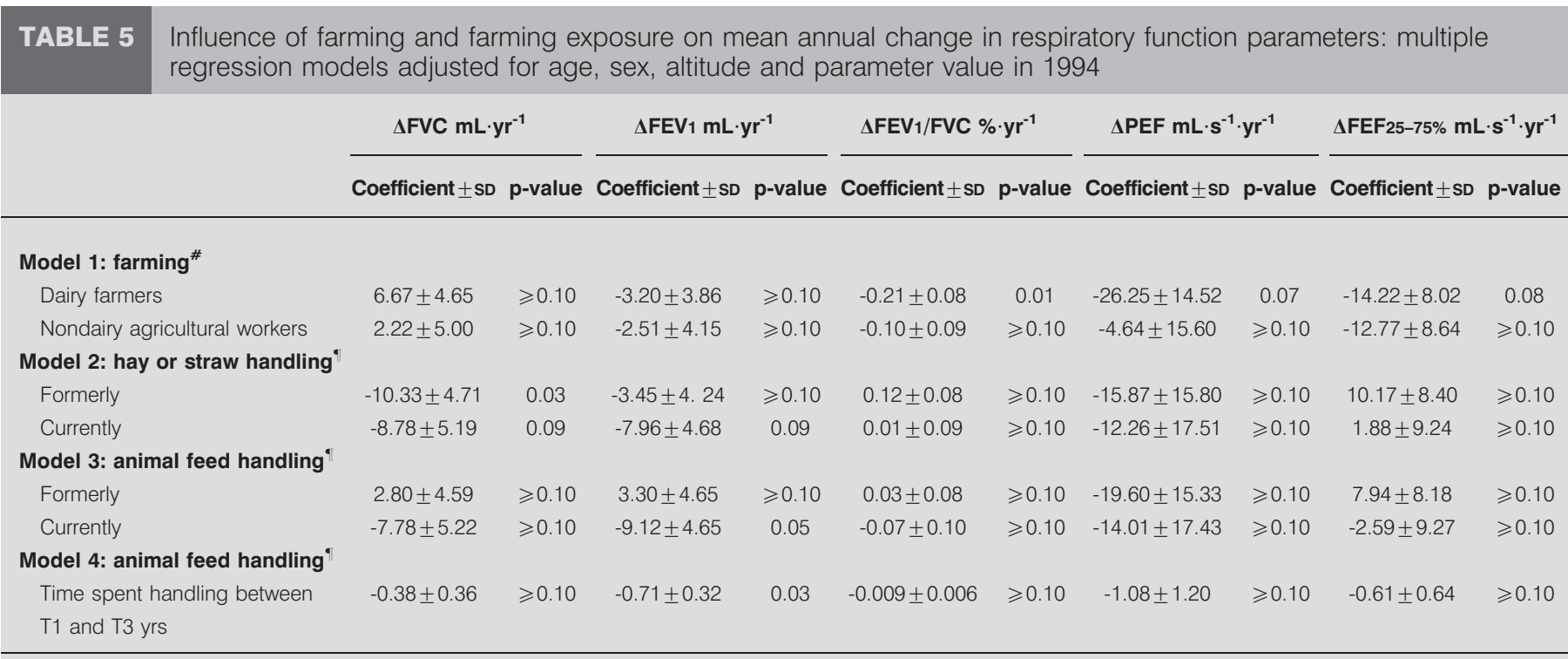

$\Delta$ : change in; FVC: forced vital capcity; FEV1: forced expiratory volume in $1 \mathrm{~s}$; PEF: peak expiratory flow; FEF25-75\%: forced expiratory flow at 25-75\% of FVC. ${ }^{\#}$ : multiple linear regressions performed in the whole cohort with adjustment for smoking status (current smokers and ex-smokers versus never-smokers), age (yrs), height (cm), sex, altitude (mountain and tableland versus plain) and analysis of the initial value of the lung function parameter; " : multiple linear regressions performed in dairy farmers and other agricultural workers with adjustment for smoking status (current smokers and ex-smokers versus never-smokers), age (yrs), height (cm), sex, altitude (mountain and tableland versus plain) and analysis of the initial value of the lung function parameter.

conclusions about the specific role of each exposure on respiratory impairment.

A second limitation concerns the differences in participation rates between the three groups. These differences were not related to increased mortality or more refusals to participate in the nondairy agricultural workers or controls than in dairy farmers. They can be explained by an excess of loss to followup in nondairy agricultural workers and controls, in that dairy farmers in our area are less likely to move than nondairy agricultural workers and administrative employees, particularly to find a new job. Subjects lost to follow-up were younger than those who participated. However it is important to note that there was no difference in respiratory symptoms or lung function parameters at baseline between subjects who participated or did not participate in the follow-up. Moreover, the differences observed at T3 in age and smoking rates between dairy farmers and nondairy agricultural workers, and controls, can be related to similar differences observed at baseline. The same differences in smoking rates have been observed in all studies conducted in the same province. However the inclusion of fewer smokers in the dairy farmer group than in the control group would only have lead to a lack of power, as smoking is related to an increased risk of lung function impairment. However, the inclusion of more older farmers than controls would have induced a selection bias, but all multiple analyses were adjusted for age.

Finally, as we did not perform post-bronchodilator spirometry, we cannot affirm that the decrease in FEV1/FVC observed in dairy farmers is related to chronic obstructive pulmonary disease, even if it is the most probably hypothesis, since dairy farmers also presented an excess risk of morning phlegm.
An excess of respiratory symptoms related to chronic bronchitis has been already found in dairy farmers from the same province $[15,16]$ and other agricultural settings (poultry workers [4, 5], pig farmers [2, 3], flower cultivators [28], grain silo workers [17] and sawmill or wood workers [29]). Conversely, the accelerated decline in FEV1/FVC that we observed over a long follow-up period has rarely been reported, and then was not reproducible within other agricultural sectors [14]. Lung function parameters and mean annual changes were correlated with smoking and age. This shows the relevance of our measures and, therefore, of our results. The decrease in $\mathrm{Sp}_{1} \mathrm{O}_{2}$ in dairy farmers might not be clinically relevant, even if at this level of the haemoglobin dissociation curve, a small variation in $\mathrm{Sp}, \mathrm{O}_{2}$ corresponds to a greater variation in arterial oxygen tension. However, this consistent finding [16, 18] probably indicates an alveolar involvement related to occupational exposure.

Our study originally found associations of hay, straw and animal feed (grains and flour) exposures with significant increased risks of asthma and wheezing. In the study by HoppIN et al. [30], handling ground animal feed and stored hay was related with an increased risk of wheeze. In addition, animal feed handling and, in particular, the number of years of exposure to animal feed was also associated with an increased decline in FEV1. In the study by EDUARD et al. [27], chronic bronchitis was significantly associated with exposure to all agents except glucans and hydrogen sulfide. In the same study there was an inverse association of FEV1 with organic dust, bacteria, endotoxins, glucans, ammonia and hydrogen sulfide. Another study carried out in the same area (Eastern FrancheComté, France and Switzerland) showed that working in a barn, particularly handling animal feed, was associated with 
high peaks of air contamination for mold and actinomycetes, as well as for poaceae pollens [31]. Conversely, the concentration of airborne bacteria was not significantly influenced by animal feed handling. Therefore, it is likely that the exposure to molds and actinomycetes contributes to the deleterious effect of exposure to hay and animal feed on respiratory status in our study. Moreover, animal feed, straw and hay handling can also induce exposure to organic dust, bacteria, mites, endotoxins, muramic acid and even-numbered carbon chain length 3-hydroxy fatty acids. [1, 32] Working on a farm is associated with exposure to numerous inflammatory substances, which could contribute to the bronchial involvement observed in our study [32]. The risk for asthma and wheezing generated by this type of exposure might also be linked to a high concentration of pollen.

A final result worth noting was the stronger effect of former exposure to hay, straw or animal feed on respiratory symptoms than the effect of current exposure (table 3 ). This can probably be explained by the selection effect induced by respiratory diseases [33]. Farmers or agricultural workers who developed respiratory diseases are likely to have stopped performing dusty tasks. Similarly, CHENARD et al. [34] found that predicted $\mathrm{FEV} 1 / \mathrm{FVC}$ ratio and $\mathrm{FEF} 25-75 \%$ at baseline were lower in subjects who stopped swine farming compared to those who continued. In the study by EDUARD et al. [27], farmers who had left farming had more chronic bronchitis, and lower FEV1 and FVC, and farmers who had changed farm production because of dust-related respiratory problems had an increased prevalence of chronic bronchitis and asthma [27].

\section{Conclusion}

Our study shows an excess of usual morning phlegm and an accelerated decline in FEV1/FVC in dairy farmers. Handling hay, straw and animal feed is probably responsible for the excess of respiratory symptoms in dairy farmers and animal feed handling is associated with an accelerated decline in FEV1. However, our data are insufficient to affirm a causal relationship and the exposure measurement needs to be refined.

\section{STATEMENT OF INTEREST}

None declared.

\section{ACKNOWLEDGEMENTS}

We wish to thank the members of the medical unit of the MSA in the Doubs, France who helped us to organise the data collection and N. Richardson-Peuteuil (independent translator-editor, Montfaucon, France) for her editorial assistance.

\section{REFERENCES}

1 Omland O. Exposure and respiratory health in farming in temperate zones: a review of the literature. Ann Agric Environ Med 2002; 9: 119-136.

2 Senthilselvan A, Chenard L, Ulmer K, et al. Excess respiratory symptoms in full-time male and female workers in large-scale swine operations. Chest 2007; 131: 1197-1204.

3 Vogelzang PF, van der Gulden JW, Tielen MJ, et al. Health-based selection for asthma, but not for chronic bronchitis, in pig farmers: an evidence-based hypothesis. Eur Respir J 1999; 13: 187-189.

4 Zuskin E, Mustajbegovic J, Schachter EN, et al. Respiratory function in poultry workers and pharmacologic characterization of poultry dust extract. Environ Res 1995; 70: 11-19.
5 Kirychuk SP, Senthilselvan A, Dosman JA, et al. Respiratory symptoms and lung function in poultry confinement workers in Western Canada. Can Respir J 2003; 10: 375-380.

6 Babbott FL Jr, Gump DW, Sylwester DL, et al. Respiratory symptoms and lung function in a sample of Vermont dairymen and industrial workers. Am J Public Health 1980; 70: 241-245.

7 Choudat D, Goehen M, Korobaeff M, et al. Respiratory symptoms and bronchial reactivity among pig and dairy farmers. Scand $J$ Work Environ Health 1994; 20: 48-54.

8 Dalphin JC, Bildstein F, Pernet D, et al. Prevalence of chronic bronchitis and respiratory function in a group of dairy farmers in the French Doubs province. Chest 1989; 95: 1244-1247.

9 Dalphin JC, Dubiez A, Monnet E, et al. Prevalence of asthma and respiratory symptoms in dairy farmers in the French province of the Doubs. Am J Respir Crit Care Med 1998; 158: 1493-1498.

10 Dosman JA, Graham BL, Hall D, et al. Respiratory symptoms and alterations in pulmonary function tests in swine producers in Saskatchewan: results of a survey of farmers. J Occup Med 1988; 30: 715-720.

11 Lamprecht B, Schirnhofer L, Kaiser B, et al. Farming and the prevalence of non-reversible airways obstruction: results from a population-based study. Am J Ind Med 2007; 50: 421-426.

12 Senthilselvan A, Dosman JA, Kirychuk SP, et al. Accelerated lung function decline in swine confinement workers. Chest 1997; 111: 1733-1741.

13 Vogelzang PF, van der Gulden JW, Folgering $\mathrm{H}$, et al. Longitudinal changes in lung function associated with aspects of swine-confinement exposure. J Occup Environ Med 1998; 40: 1048-1052.

14 Pahwa P, Senthilselvan A, McDuffie $\mathrm{HH}$, et al. Longitudinal decline in lung function measurements among Saskatchewan grain workers. Can Respir J 2003; 10: 135-141.

15 Dalphin JC, Maheu MF, Dussaucy A, et al. Six year longitudinal study of respiratory function in dairy farmers in the Doubs province. Eur Respir J 1998; 11: 1287-1293.

16 Gainet M, Thaon I, Westeel V, et al. Twelve-year longitudinal study of respiratory status in dairy farmers. Eur Respir J 2007; 30: 97-103.

17 Chan-Yeung M, Dimich-Ward H, Enarson DA, et al. Five crosssectional studies of grain elevator workers. Am J Epidemiol 1992; 136: $1269-1279$.

18 Chaudemanche H, Monnet E, Westeel V, et al. Respiratory status in dairy farmers in France; cross sectional and longitudinal analyses. Occup Environ Med 2003; 60: 858-863.

19 Ferris BG. Epidemiology Standardization Project (American Thoracic Society). Am Rev Respir Dis 1978; 118: 1-120.

20 Burney PG, Luczynska C, Chinn S, et al. The European Community Respiratory Health Survey. Eur Respir J 1994; 7: 954-960.

21 Standardization of Spirometry, 1994 Update. American Thoracic Society. Am J Respir Crit Care Med 1995; 152: 1107-1136.

22 Quanjer PH. Standardized lung function testing. Bull Eur Physiopath Respir 1983; 19: Suppl. 5, 5-95.

23 Dalphin JC, Pernet D, Reboux G, et al. Influence of mode of storage and drying of fodder on thermophilic actinomycete aerocontamination in dairy farms of the Doubs region of France. Thorax 1991; 46: 619-623.

24 Reboux G, Reiman M, Roussel S, et al. Impact of agricultural practices on microbiology of hay, silage and flour on Finnish and French farms. Ann Agric Environ Med 2006; 13: 267-273.

25 Gbaguidi-Haore H, Roussel S, Reboux G, et al. Multilevel analysis of the impact of environmental factors and agricultural practices on the concentration in hay of microorganisms responsible for farmer's lung disease. Ann Agric Environ Med 2009; 16: 219-225. 
26 Roussel S, Reboux G, Dalphin JC, et al. Microbiological evolution of hay and relapse in patients with farmer's lung. Occup Environ Med 2004; 61: e3.

27 Eduard W, Pearce N, Douwes J. Chronic bronchitis, COPD, and lung function in farmers: the role of biological agents. Chest 2009; 136: 716-725.

28 Monso E, Magarolas R, Radon K, et al. Respiratory symptoms of obstructive lung disease in European crop farmers. Am J Respir Crit Care Med 2000; 162: 1246-1250.

29 Halpin DM, Graneek BJ, Lacey J, et al. Respiratory symptoms, immunological responses, and aeroallergen concentrations at a sawmill. Occup Environ Med 1994; 51: 165-172.

30 Hoppin JA, Umbach DM, London SJ, et al. Animal production and wheeze in the Agricultural Health Study: interactions with atopy, asthma, and smoking. Occup Environ Med 2003; 60: e3.
31 dairymenSudre B, Vacheyrou M, Braun-Fahrlander C, et al. High levels of grass pollen inside European dairy farms: a role for the allergy-protective effects of environment? Allergy 2009; 64: 1068-1073.

32 Poole JA, Dooley GP, Saito R, et al. Muramic acid, endotoxin, 3hydroxy fatty acids, and ergosterol content explain monocyte and epithelial cell inflammatory responses to agricultural dusts. J Toxicol Environ Health 2010; 73: 684-700.

33 Post W, Heederik D, Houba R. Decline in lung function related to exposure and selection processes among workers in the grain processing and animal feed industry. Occup Environ Med 1998; 55: 349-355.

34 Chenard L, Senthilselvan A, Grover VK, et al. Lung function and farm size predict healthy worker effect in swine farmers. Chest 2007; 131: 245-254. 